\title{
Estudo do Tubo de Vórtices no Torneamento
}

Davi Pires Araújo, Denis Barbosa Souza, Danilo dos Santos Oliveira, Jhon Goulart, Rhander Viana

Universidade de Brasília - Faculdade do Gama (UnB/FGA)

Área Especial 2 Lote 14 Setor Central - 72405-610 Gama, DF, Brasil - Telf: +55 613384

E-mail: davidaviaraujo@hotmail.com,denis_dbs@hotmail.com,jvazgoulart@gmail.com, rhanderviana@gmail.com

\section{RESUMO}

O tubo de vórtices é um dispositivo mecânico utilizado na conversão de energia cinética do ar em energia térmica. O objetivo deste trabalho é analisar o tubo de vórtices no processo de torneamento, especificamente, no faceamento rápido de um aço ABNT 1045 utilizando ferramentas de aço rápido com $10 \%$ de Co. Os resultados mostraram que no faceamento rápido utilizando o tubo de vórtices, a vida da ferramenta aumentou em $20 \%$ em relação ao processo a seco, uma vez que o colapso da ferramenta ocorreu com diâmetro de usinagem de $198,20 \mathrm{~mm}$.

\section{INTRODUÇÃO}

Ranque em 1930 projetou um dispositivo mecânico capaz de gerar dois fluxos em sentidos contrários com temperaturas diferentes, baseando-se exclusivamente na sua geometria, com apenas uma entrada de fluido de gás comprimido. Este equipamento ficou conhecido como tubo vórtice. Válvulas podem ser adicionadas para auxiliar no escoamento do fluido e para regular a quantidade de saída mássica de ar frio e quente.

Existem diversas teorias que tentam explicar o fenômeno que ocorre para que haja a separação térmica. A que há mais adeptos, é que os vórtices internos e externos possuem mesma direção e velocidade angular. O princípio da conservação do momento angular garante que o fluxo interno deveria ser maior que o externo, porém neste caso ele é violado, os fluxos possuem a mesma velocidade. $\mathrm{O}$ vórtice externo se aquece devido à energia perdida pelo vórtice interno. Dessa maneira, há a separação térmica, o fluxo externo se aquece e o interno se resfria (Gao, 2005). $127^{\circ} \mathrm{C}$.

As temperaturas alcançadas por este tubo são significativas, variando entre $-46^{\circ} \mathrm{C}$ a

O dispositivo com saída de ar do tipo unifluxo é dado pela saída de ar em apenas uma direção e sentido, tendo assim apenas uma entrada e uma saída de ar. A Figura (1) demonstra o princípio do funcionamento desta configuração. $\mathrm{O}$ ar comprimido é injetado tangencialmente na câmara de vórtice, e são gerados dois fluxos. O fluxo interno é responsável pela saída de ar frio, e o externo pela saída de ar quente, ambos possuem o 
mesmo sentido. A separação térmica é realizada por uma válvula na extremidade do tubo. Esta maneira com o que os fluxos de ar saem para atmosfera, ocasiona em uma baixa utilização desta configuração (Cockerill, 1998).

As análises feitas se basearam na vida da ferramenta de aço rápido com $10 \% \mathrm{Co}$. O processo de torneamento foi utilizado para tal ensaio. Sendo que o para o faceamento rápido o avanço e a profundidade de corte são invariantes no tempo. $\mathrm{O}$ principal ponto que irá se modificar neste experimento será a velocidade de corte, com isto a ferramenta de corte virá ao colapso.

A Figura (1) explicita a nomenclatura dos componentes do tubo de vórtices.

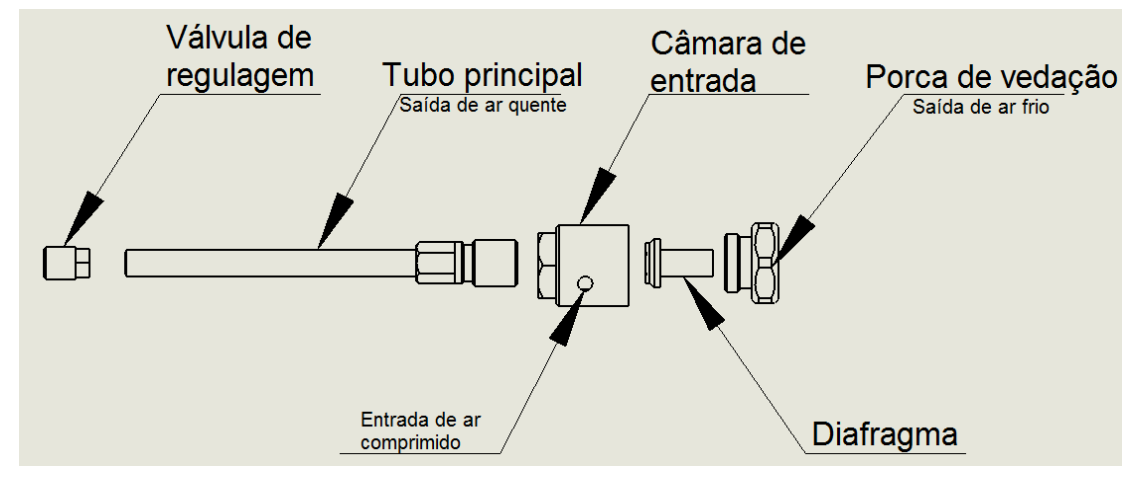

Figura 1 - Componentes do tubo de vórtices (Fonte: Autores, 2016).

\section{METODOLOGIA E DESENVOLVIMENTO}

Afim de verificar o desempenho do tubo de vórtices quanto a temperaturas de saída de ar frio como saída de ar quente, algumas técnicas de medições podem ser aplicadas. Alguns pesquisadores desenvolveram a técnica termográfica de infravermelhos atuando a investigação de temperatura sobre o ponto de corte da ponta da ferramenta. Esta técnica consiste em análise não destrutiva, além de se tratar de um exame térmico rápido com larga escala de capacidade de detecção de ondas térmicas a partir de uma certa distância.

Atualmente são preferíveis câmeras de alta resolução pelo fato desta possuir uma maior capacidade de obtenção com grante capacidade de memória e capacidade de realizar processos complexo. A configuração experimental por meio de câmera termográfica é simples podendo ser adaptada a qualquer projeto e processo de usinagem afim de obter temperaturas a partir imagens elaboradas pela câmera. A Figura 2 exemplifica uma configuração da disposição da câmera térmica no processo de torneamento utilizando tubo de vórtices. 


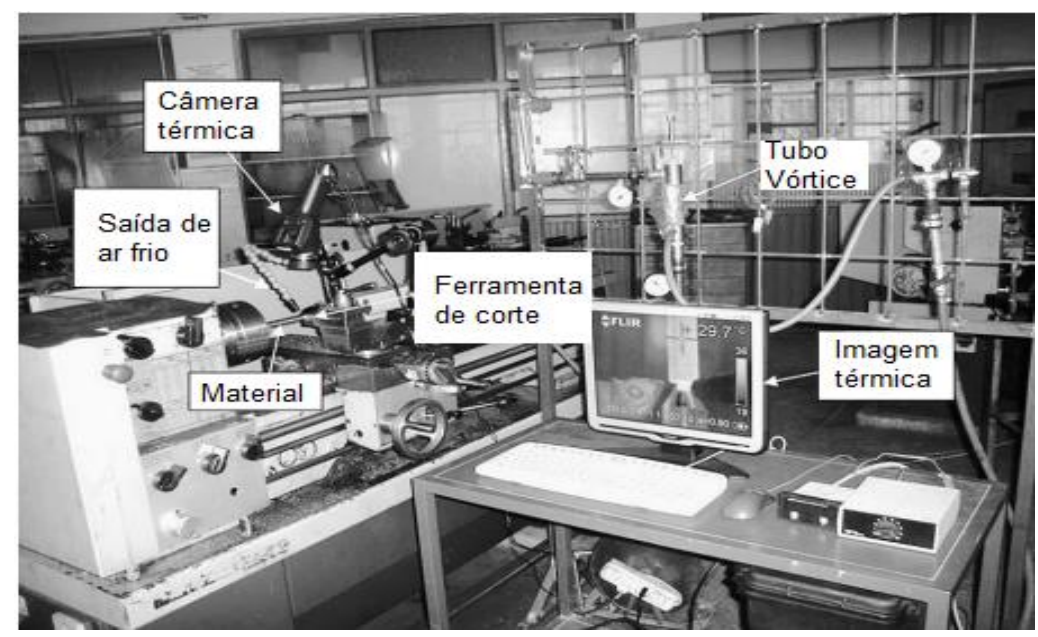

Figura 2 - Configuração experimental - Câmera Termográfica. Fonte: (Adaptado de Selek et al., 2010)

No processo de usinagem a diminuição da temperatura em que a ferramenta trabalha traz consigo vários benefícios, tais como aumento da vida útil da ferramenta, diminuição da rugosidade da peça. Além disso, no caso do tubo de vórtices, é um dispositivo ecologicamente correto não necessitando utilização de óleos lubrificantes ou refrigerantes. No Gráfico 1 podemos observar a redução da rugosidade utilizando o tubo de vórtices no processo de fresamento CNC com uma ferramenta Sandvik. A comparação do processo de fresamento com tubo de vórtices e com fluido de corte é mostrada a seguir.

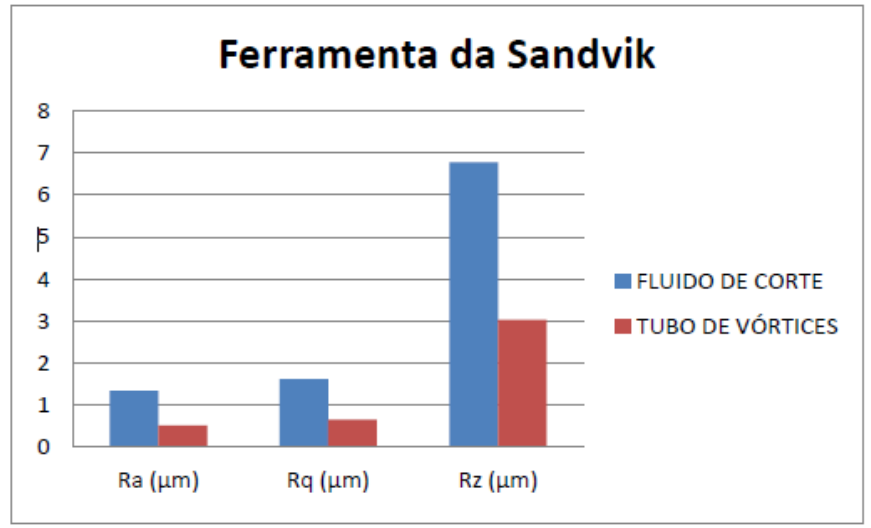

Gráfico 1- Rugosidade da peça usinada com a ferramenta Sandvik. Fonte: (Nogueira R.S. et $a l ., 2015)$

\section{ANÁLISE EXPERIMENTAL}

As análises efetuadas a fim de verificar o desempenho de um tubo de vórtices quanto a temperaturas de saída de ar fria quanto saída de ar quente foram elaboradas com a utilização de uma câmera termográfica. A área de medição da temperatura foi pintada de 
preto fosca a fim de obter resultados mais próximos do real. As temperaturas obtidas foram submetidas as condições de um tubo de vórtices com entrada de 7,89 bar de pressão, a calibragem instrumento de medição foi feita antes da medição. Na Figura 3 (a) podemos observar a temperatura do tubo próximo na saída de ar frio. Na Figura 3 (b) podemos observar a temperatura do tubo próximo na saída de ar quente.

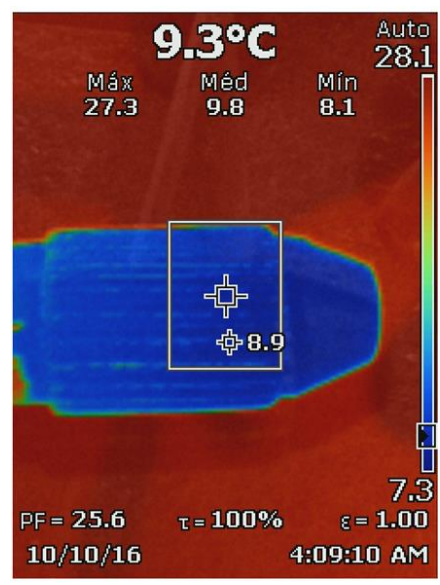

(a)

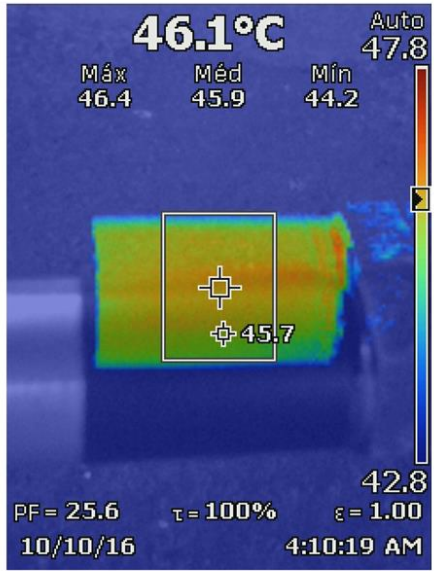

(b)

Figura 3 - Temperaturas nas saídas de ar do tubo de vórtices: (a) saída de ar frio; (b) saída de ar quente. Fonte: (Próprios autores, 2016)

\section{CONCLUSÕES}

Deste estudo inicial do tubo de vórtices conclui-se que a utilização do mesmo no processo de usinagem conduz a resultados melhores. Tais resultados obtidos foram significativos para o objetivo do trabalho, tendo em vista baixas temperaturas para a saída de ar frio.

\section{REFERÊNCIAS}

1. Cockerrill T. Thermodynamics and Fluid Mechanics of a Ranque - Hilsch Vortex Tube, University of Cambridge, 1998.

2. Gao, C. Experimental Study on the Ranque-Hilsch Vortex Tube, Tese de PhD, University of Tecnology, Eindhoven, 2005.

3. Nogueira R.S., Giaconete H. Refrigeração do processo de fresamento do aço ABNT 8640 com auxílio de tubo de vórtices. Trabalho de conclusão de curso, Universidade Paulista, 2015. 